\title{
Investigation of Proactive Personality Characteristics of the Students of High School of Physical Education and Sports through Various Variables
}

\author{
Burhan Ozkurt ${ }^{1}$ \\ Cemal Berkan Alpay ${ }^{2}$ \\ ${ }^{2}$ Ministry of Interior, Batman Provincial Police Headquarters, Batman, Turkey \\ Email:b oakurt@hotmail.com \\ 'Department of Coaching, Omer Halisdemir University, Nigde, Turkey \\ Email:berkanalpay@hotmail.com
}

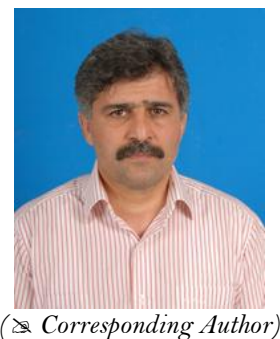

\begin{abstract}
The purpose of this study is to determine the personality characteristics of the students who study at the High School of Physical Education and Sports and to determine the differences between the personalities according to the demographic characteristics of them. The "Proactive Personality Scale" was used for collecting research data. Independent t-test was used for two groups and the one-way analysis of variance for more than two groups in the comparison of the subjects' opinions, in terms of the proactive personality traits, according to their individual characteristics. As a conclusion, though there were no statistically significant difference between gender, number of siblings, environment they lived in, sports branches, education level of mother, education level of father, and income levels of the students participated in the survey ( $p>0,05)$, significant difference was detected in terms of sporting status, sport ages, achievement levels, and family income levels of $(\mathrm{p}<0.05)$.
\end{abstract}

Keywords: Physical education and sports, Proactive personality, University students.

JEL Classification: P36 Education and Training

Citation | Burhan Ozkurt; Cemal Berkan Alpay (2018). Investigation of Proactive Personality Characteristics of the Students of High School of Physical Education and Sports through Various Variables. Asian Journal of Education and Training, 4(2): 150-155.

History:

Received: 24 August 2016

Revised: 1 September 2016

Accepted: 26 September 2016

Published: 23 April 2018

Licensed: This work is licensed under a Creative Commons Attribution 3.0 License (cc) $\mathrm{Er}$

Publisher:Asian Online Journal Publishing Group
Contribution/Acknowledgement: Both authors contributed to the conception and design of the study.

Funding: This study received no specific financial support.

Competing Interests: The authors declare that they have no conflict of interests.

Transparency: The authors confirm that the manuscript is an honest, accurate, and transparent account of the study was reported; that no vital features of the study have been omitted; and that any discrepancies from the study as planned have been explained.

Ethical: This study follows all ethical practices during writing.

\section{Contents}

1. Introduction

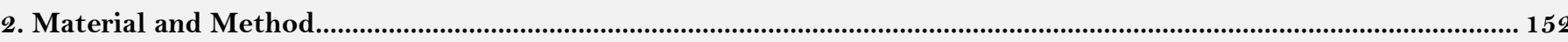

3. Results .......... 159

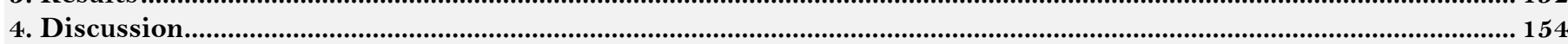

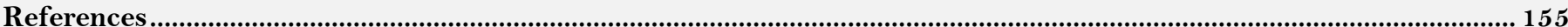




\section{Introduction}

Some new concepts have been taking their parts in our lives along with today's changing conditions. These concepts influence our lifestyle, our point of view for the world, our relationships, and our plans for the future. One of these concepts is proactive personality. The proactive personality was found to be worthy of investigation because of things it presented to persons and, meanwhile, the advantages it provided to the community and business life; its effectiveness in increasing the quality of life, and the fact that the work done in this country is not sufficient. The proactivity, which can be found in all areas of life influenced by the human factor, is defined as the difference in the mental structure of people in a movement or initiative to influence the environment they live in (Bateman and Crant, 1993). This difference helps also to identify the proactive personality. When the concept of the proactive personality is examined in general terms, it is defined by a personality structure that performs risk analysis, not quitting control means, taking risks in place and on a good time, and able to teach a life lesson even from failures. The proactive personality is characterized by a pattern of self-peaceful, self-esteemed, and high selfrespect behavior. The ones who are in this personality profile perform "every elective behavior as a unit" as a result of reasoning and risk analysis. They use their knowledge and intellectual abilities together with their common sense. There is a symphonic harmony between their cognitive intelligence, emotional intelligence, and spiritual intelligence. They confront their concerns with reality. They approach the reality realistically. They pass their fear and anxiety through the "reality filter". Thanks also to these personality patterns, they assimilate to learn in every field of life. They convert their troubles and mistakes into a new learning experience and life-style. They confront their problems, using all of their existential energies at a high level. They do not leave the control means untouched. They do not part from their internal disciplines. They are willing, at all costs, to try and learn. They learn the truth from mistakes when they make mistakes and the perfection of the truth when they do right. The individuals with the proactive personality patterns internalize by rationalization the problem subjects outside of themselves. They pass the problems through the reality filter to make their internal world accept them. That is, the process cannot direct him or her, on the contrary, he/she continues on his/her way and so, he/she can distribute his/her energy and performance throughout life (Sahin, 2006).

The proactive personality behaviors are accepted as conscious and pre-assumed behaviors. While explaining the proactive personality, Baltaş (2008) stated that the individuals acted for their behavior purposefully, and the aim prompted them to create an effect that would cause a change. The proactive individuals perform very well for participating in different activities, performing successful exchanges, and going beyond expectations. The proactive ones have a belief that they can change, as a result of their behavior, the conditions. For this reason, they tend towards entrepreneurial actions. They become a pioneer and active participant of change. The proactive persons do not stop at designing and launching change, but they end up it and so succeed. They are defined as the ones who try to arrive at a target and be successful by really making an effort to get whatsoever is to be performed (Baltaş, 2005). They will, in other words, not only change the existing conditions but will endeavor to develop the existing conditions in accordance with their aims in order to achieve a successful result.

Webster's Medical Dictionary (2002) defines the proactive person as "the one who can perform the appropriate action, not after the problem has arisen, but before the problem has emerged." In this sense, it is expressed that the proactive person constitutes strong predictions for the opportunities and risks in which he/she assesses the current situation. The proactive personality is defined as a person who takes initiative to create new conditions by discovering opportunities besides developing current conditions, persevering until there is a meaningful change rather than passively adapting to the existing conditions (Crant, 2000). The proactive ones do not progress through only one solution to the conditions they want to create. They always have a backup plan and an alternative solution and they have more self-discipline than other people. They make a case evaluation for the difficulties they face in life and make effort to reach a better result. They are aware of their responsibilities. They are, therewithal, more likely to succeed because they not only accept their faults of behavior but also try to change them (Çini, 2014). That their progressing, not insisting on their mistakes, but taking lessons from mistakes, shows that their awareness is high and they are exposed to development.

Since the proactive approach drives persons for attention and thought, the ones with this approach have the opportunity to foresee and evaluate the opportunities prior to others. They are competent in adapting to new conditions. Because of systematic thought structures, they determine their targets easily and reach the result. The proactive ones try to create new environmental conditions by determining conditions that are not suitable for their values in the environment they are in since they are change-oriented (Van and De, 2012).

It can be observed that the proactive people constitute, by the help of the features they possess, their own values and apply their values in their lives. While the behaviors of others are determined by their surroundings, the proactive individuals do not forget their true values and so they choose their own actions themselves. The proactive individual has a vision. He has assigned his vision to reach his goals and works for it, creating the meaning of his life. For example, politicians, business people, teachers, and athletes can dream of contesting with others, but these are not imaginary, and they imagine the things that might be and set out their goals through their visions (Schwarzer, 1999).

The proactive individuals are counterparts for the active individual needs of the community through their available features and the structures that will make their presence felt in social life. It is solid that the ones with the proactive personality traits will also be involved in all areas of life. It is expected, as in other fields, that these personality traits will be actively involved in also sports and education fields. It is important to trace the proactive traits and determine the contributions of it to both life and him/her through the characteristics they put forward. The aim of this study was, in the light of the information forgiven, to determine the proactive personality profiles of the students who study at the High School of Physical Education and Sports and to examine the differences between various variables and proactive personality traits. 


\section{Material and Method \\ 2.1. Subjects}

Total 1432 students, 847 of the males and 585 females, ages ranging between 18 and 47, studying at different departments of the High School of Physical Education and Sports from 28 Universities located on 7 regions of Turkey during the 2014 to 2015 Education-Teaching Year, participated voluntarily in the research.

\subsection{Proactive Personality Scale}

The proactive personality scale developed by Bateman and Crant (1993) and adapted to Turkish by Akın et al. (2011) was used to determine the personality traits of the students attending the High School of Physical Education and Sports. The Proactive Personality Scale is one-dimensional and consists of 17 items. The scale consisting of total 17 items is of septate (with 7) Likert type and is graded between 1 and 7 (1: Absolutely Disagree, 2: Disagree, 3: Partially Disagree, 4: Undecided, 5: Partially Agree, 6: Agree, 7: Absolutely Agree). The reliability coefficient of the scale used in this study was determined through the Cronbach's Alpha values and found to be 0.93.

\subsection{Data Collecting}

The students from the High School of Physical Education and Sports were randomly selected and they volunteered to participate in the study. The questionnaire (survey) technique was used as a data collecting means in the research. 1500 questionnaires were distributed and 1432 questionnaires total were used as data.

\subsection{Statistical Analysis of Data}

The Statistical Package for Social Sciences (SPSS) 18.0 program was used for the analysis of the data obtained. The independent samples t-test for two groups and One-way ANOVA for multiple groups were used to compare subjects' opinions on proactive personality traits according to their individual characteristics. The Tukey test was applied, therefore, to determine from which group or groups the group differences was/were emerged. The confidence range was chosen as $95 \%$ and the values below $\mathrm{p}<0.05$ were considered statistically significant.

\section{Results}

The results obtained by comparing the opinions of students, who participated in the questionnaire(s), for the scale applied in the study to their personal characteristics are as follows:

Table-1. Comparison of subjects' views by gender

\begin{tabular}{l|l|l|l|l|l|l}
\hline Variables & Gender & $\mathbf{N}$ & $\overline{\mathrm{X}}$ & S.D. & T & $\mathbf{p}$ \\
\hline \multirow{2}{*}{ Proactive Personality } & Male & 847 & 5,34 & 1,10 & $-0,465$ & 0,642 \\
\cline { 2 - 7 } & Female & 585 & 5,36 & 1,10 & $-0,46$ \\
\hline
\end{tabular}

That the subjects' proactive personality traits did not show any significant difference according to gender is clear as indicated above $(\mathrm{p}>0.05)$.

Table-2. Comparison of subjects' views by age groups

\begin{tabular}{|c|c|c|c|c|c|c|}
\hline Variables & Age group & $\mathbf{N}$ & $\bar{X}$ & S.D. & $\mathbf{F}$ & $\mathbf{p}$ \\
\hline \multirow{3}{*}{ Proactive Personality } & $16-20$ & 559 & $5,42^{\mathrm{a}}$ & 1,08 & \multirow{3}{*}{3,846} & \multirow{3}{*}{$0,022^{*}$} \\
\hline & $21-25$ & 758 & $5,28^{\mathrm{b}}$ & 1,11 & & \\
\hline & $\geq 26$ & 115 & $5,49^{\mathrm{a}}$ & 1,09 & & \\
\hline
\end{tabular}

That the subjects' attitudes towards the proactive personality characteristics showed significant difference according to age groups $(\mathrm{p}<0,05)$ is obvious. When the average values in Table 2 are taken into account, the age group of $16-20$ years $($ Mean=5.42) and the age group of 26 and above (Mean=5.49) are statistically similar while the age group of 21-25 years (Mean=5.28) have low mean and so considered statistically different.

\begin{tabular}{|c|c|c|c|c|c|c|}
\hline Scale & Sibling Number & $\mathbf{N}$ & $\bar{X}$ & S.D. & $\mathbf{F}$ & $\mathbf{p}$ \\
\hline \multirow{3}{*}{ Proactive Personality } & $0-2$ & 438 & 5,36 & 1,06 & \multirow{3}{*}{0,711} & \multirow{3}{*}{0,491} \\
\hline & $3-5$ & 755 & 5,37 & 1,1 & & \\
\hline & $\geq 6$ & 239 & 5,27 & 1,15 & & \\
\hline
\end{tabular}

That the subjects' proactive personality traits did not differ significantly from the sibling group ( $\mathrm{p}>0,05)$ is obvious as shown.

Table-4. Comparison of subjects' views according to locations they live in

\begin{tabular}{|c|c|c|c|c|c|c|}
\hline Scale & The location they live in & $\mathbf{N}$ & $\bar{X}$ & S.D. & $\mathbf{F}$ & $\mathbf{p}$ \\
\hline \multirow{5}{*}{ Proactive Personality } & Village & 92 & 5,34 & 1,12 & \multirow{5}{*}{0,475} & \multirow{5}{*}{0,754} \\
\hline & Town & 54 & 5,31 & 1,05 & & \\
\hline & District & 327 & 5,28 & 1,10 & & \\
\hline & Province & 919 & 5,38 & 1,10 & & \\
\hline & Abroad & 40 & 5,34 & 1,16 & & \\
\hline
\end{tabular}


That the subjects' proactive personality traits did not show any significant difference compared to places where they have lived is shown above $(\mathrm{p}>0.05)$.

Table-5. Comparison of subjects' views per the sports branches

\begin{tabular}{l|l|l|l|l|l|l}
\hline \multirow{2}{*}{ Scale } & Branch & $\mathbf{N}$ & $\bar{X}$ & S.D. & T & $\mathbf{p}$ \\
\hline \multirow{2}{*}{ Proactive Personality } & Individual & 739 & 5,33 & 1,11 & \multirow{2}{*}{$-0,823$} & 0,411 \\
\cline { 2 - 8 } & Team & 693 & 5,37 & 1,09 & \\
\hline
\end{tabular}

It is clear from the Table above that the subjects' proactive personality traits did not differ significantly in terms of the sports branches $(\mathrm{p}>0,05)$.

\begin{tabular}{|c|c|c|c|c|c|c|}
\hline Scale & Educational status & $\mathbf{N}$ & $\mathrm{X}$ & S.D. & $\mathbf{F}$ & $\mathbf{p}$ \\
\hline \multirow{5}{*}{ Proactive Personality } & None & 115 & 5,47 & 1,07 & \multirow{5}{*}{1,385} & \multirow{5}{*}{0,227} \\
\hline & Primary school & 653 & 5,31 & 1,13 & & \\
\hline & Secondary School & 307 & 5,4 & 1,03 & & \\
\hline & High School & 257 & 5,39 & 1,07 & & \\
\hline & University & 94 & 5,26 & 1,21 & & \\
\hline
\end{tabular}

$\mathrm{p}>0,05$

That the subjects' proactive personality traits did not show any significant difference in terms of their mothers' education level is indicated above $(\mathrm{p}>0,05)$.

\begin{tabular}{|c|c|c|c|c|c|c|}
\hline Scale & Educational Status & $\mathbf{N}$ & $X$ & S.D. & $\mathbf{F}$ & $\mathbf{p}$ \\
\hline \multirow{6}{*}{ Proactive Personality } & None & 65 & 5,45 & 1,17 & \multirow{6}{*}{1,047} & \multirow{6}{*}{0,389} \\
\hline & Primary school & 441 & 5,30 & 1,17 & & \\
\hline & Secondary School & 347 & 5,37 & 1,01 & & \\
\hline & High School & 386 & 5,40 & 1,05 & & \\
\hline & University & 183 & 5,31 & 1,16 & & \\
\hline & Postgraduate & 10 & 4,79 & 0,97 & & \\
\hline
\end{tabular}

$\mathrm{p}>0,05$

It is shown in the Table above that the opinions of the subjects about the proactive personality traits did not show any significant difference in terms of the father education level $(p>0,05)$.

\begin{tabular}{|c|c|c|c|c|c|c|}
\hline Scale & Family Monthly Income & $\mathbf{N}$ & $X$ & S.D. & $\mathbf{F}$ & $\mathbf{p}$ \\
\hline \multirow{3}{*}{ Proactive Personality } & $0-1000 \square$ & 357 & $5,19^{\mathrm{a}}$ & 1,17 & \multirow{3}{*}{4,742} & \multirow{3}{*}{0,009} \\
\hline & $1001-2000 \square$ & 810 & $5,40^{\mathrm{b}}$ & 1,03 & & \\
\hline & 2000 and over $\square$ & 265 & $5,39^{\mathrm{b}}$ & 1,17 & & \\
\hline
\end{tabular}

* $\mathrm{p}<0.05 ;$ a, b Different letters represent inter-group differences.

The attitudes of subjects towards the proactive personality characteristics showed significant differences in terms of family monthly income $(\mathrm{p}<0,05)$. When the average values in Table 8 are taken into consideration, the average monthly income level between $\square 0$ to 1000 (Mean=5,19) and $\square 1001$ to 2000 (Mean=5.40), and $\square 2000$ and above (Mean=5.39) are statistically different from each other.

Table-9. Comparison of subjects' views according to their own monthly income

\begin{tabular}{|c|c|c|c|c|c|c|}
\hline Scale & Monthly Income & $\mathbf{N}$ & $\bar{X}$ & S.D. & $\mathbf{F}$ & $\mathbf{p}$ \\
\hline & $0-330 \square$ & 738 & 5,36 & 1,09 & & \multirow{3}{*}{0,940} \\
\hline \multirow[t]{2}{*}{ Proactive Personality } & $331-660 \square$ & 263 & 5,35 & 1,17 & 0,062 & \\
\hline & 661 and over $\square$ & 431 & 5,33 & 1,07 & & \\
\hline
\end{tabular}

That the subjects' proactive personality traits did not differ significantly in terms of their monthly income is clear from the Table above ( $\mathrm{p}>0.05)$.

Table-10. Comparison of subjects' views by sports age groups

\begin{tabular}{|c|c|c|c|c|c|c|}
\hline Scale & Sports Age Group & $\mathbf{N}$ & $\bar{X}$ & S.D. & $\mathbf{F}$ & $\mathbf{p}$ \\
\hline \multirow{3}{*}{$\begin{array}{l}\text { Proactive } \\
\text { Personality }\end{array}$} & $1-5$ & 552 & $5,22^{\mathrm{a}}$ & 1,08 & \multirow{3}{*}{6,305} & \multirow{3}{*}{$0,002 *$} \\
\hline & $6-10$ & 599 & $5,42^{\mathrm{b}}$ & 1,1 & & \\
\hline & $>10$ & 281 & $5,45^{\mathrm{b}}$ & 1,11 & & \\
\hline
\end{tabular}

The attitudes of subjects towards the proactive personality characteristics were significantly different in terms of sports age groups $(\mathrm{p}<0,05)$. When the averages in Table 10 are taken into consideration, the average of 1 to 5 
sports age group (Mean=5,22), 6 to 10 sports age group (Mean=5.42), and 11 and above sports age group $(\mathrm{Mean}=5.45)$ were statistically different from each other.

Table-11. Comparison of subjects' views according to the sports achievement scores

\begin{tabular}{l|l|l|l|l|l|l|l}
\hline Scale & Degree & $\mathbf{N}$ & $\overline{\mathbf{X}}$ & S.D. & $\mathbf{F}$ & $\mathbf{p}$ \\
\hline \multirow{3}{*}{ Proactive Personality } & No degree & 778 & $5,26^{\mathrm{a}}$ & 1,15 & & \multirow{3}{*}{$0,004^{*}$} \\
\cline { 2 - 5 } & National success & 539 & $5,47^{\mathrm{b}}$ & 0,98 & 5,480 & \multirow{2}{*}{} \\
\cline { 2 - 5 } & International success & 115 & $5,38^{\mathrm{ab}}$ & 1,25 & & \\
\hline
\end{tabular}

* $\mathrm{p}<0.05 ;{ }^{\mathrm{a}, \mathrm{b}}$ Different letters represent inter-group differences.

The attitudes of subjects towards proactive personality characteristics showed significant differences according to their grade status $(\mathrm{p}<0,05)$. When the averages in Table 11 were taken into account, it was determined that the students with no degrees had lower proactive personality traits (Mean=5.26) than those with both national success $($ Mean $=5.47)$ and international success $($ Mean= 5.38).

Table-12. Comparison of subjects' views according to taking part in sports activities

\begin{tabular}{l|l|l|l|l|l|l|}
\hline Scale & Engaged in Sports & $\mathbf{N}$ & $\bar{X}$ & S.D. & F & $\mathbf{p}$ \\
\hline \multirow{4}{*}{ Proactive Personality } & No, I'm not engaged in sports. & 166 & $5,16^{\mathrm{a}}$ & 1,19 & \\
\cline { 2 - 7 } & Yes, I'm on the school team. & 186 & $5,40^{\mathrm{b}}$ & 1,09 \\
\cline { 2 - 7 } & Yes, I am a licensed sportsman in a club. & 588 & $5,42^{\mathrm{b}}$ & 1,04 & 2,787 \\
\cline { 2 - 6 } & Yes, I'm not licensed, but I do sports on certain days. & 492 & $5,31^{\mathrm{b}}$ & 1,13 & \\
\hline
\end{tabular}

*p $<0.05 ;$ a, b Different letters represent inter-group differences.

Table 12 gives the results of variance analysis on the comparison of subjects' views on the scale with respect to their sporting status. It is clear, as shown above, that the subjects' proactive personality traits were significantly different in terms of their sports activities $(p<0,05)$. If we take into account the averages in Table 11 , the average of the ones claiming that "No, I'm not engaged in sports" (Mean=5,16) is lower than the averages of the ones claiming "Yes, I am on the school team" (Mean=5,40), "Yes, I am a licensed sportsman in a club" (Mean=5,42), and "Yes, I am not a sportsman, but I do sports on certain days" (Mean=5,31).

\section{Discussion}

In this research, the proactive personality traits of the students attending the High School of Physical Education and sports were examined through miscellaneous variables. An answer is looked for, also, the questions whether the aspects of the students such as age, gender, number of siblings, sports activities, sports branches they engaged in, maternal and paternal educational status, monthly income levels, sports age, family income levels, highest achievement obtained, economic status, surroundings they live in etc. were differentiated or not per the independent variables. It has been found that the proactive personality plays an important role in the quality of life based on the findings obtained by examining the previous studies accomplished on this subject and analyzing the findings during the adaptation period of the scale.

No significant difference is observed, according to research findings, in the distribution of the subjects in terms of their proactive personality characteristics and their genders. Karasu (2013) compared, in his study, the autonomy development, attachment styles, and proactive personality structures of the students and concluded that there was no significant difference, per the t-test results, in the autonomy development in terms of gender.

It is clear that the respondents did not show any significant difference according to the results of variance analysis on the comparison of the scale-oriented opinions of the subjects in terms of the places they live in. The results of the study conducted by Sahin (2006) in his research gives support to our findings and, according to the results of this research, the proactive handling and handling strategies that we consider as sub-dimensions are the gains that are acquired later and can only be developed by the individual at his/her own will. That having these gains, meanwhile, is not much affected by the environmental conditions.

The researches about the proactive personality traits and sporting situations have been investigated and the findings obtained have been supporting the researches accomplished. A significant relationship was detected between the proactive personality traits and sporting situations. Bayar (2003) notes that the ladies engaged in sports are the ones who are more extrovert, adventurous, with high the risk-taking feature, docile, normative, obedient, generally more rigid, talented, emotionally balanced, and with high confidence in themselves.

When the questions regarding the comparison of subjects' views on the scale with respect to the sports branches are examined, on the other hand, it is clear that the opinions about the proactive personality characteristics of the subjects did not show any significant difference compared to the sports branches. Cetinöz (2005) concluded, in his study comparing personality traits, that the individual athletes were more determined, responsible, and mature than the team athletes.

When we analyzed the comparison of the results of variance analysis to the views of subjects on the scale, therefore, it is clear that the opinions about the proactive personality characteristics of the subjects have shown the significant difference compared to the sports age groups. Hoffstetter et al. (1990) revealed, in their studies, the correlation between the ones beginning sports at the ages of 6-14 for primary education, 15-18 ages for secondary education, and during higher education and regularly performed sports activities of the adults, social learning, and sports activities in terms of social competence expectancy. It is known that an early start to make sports has many advantages. It is well known that not only some important factors such as the prevention of health problems and obesity can be prevented for the ones engaged in sports for long times, but it also helps them to attain some important capabilities such as the rules included within the sports, self-discipline, coping with competition, trying again, aiming for a given purpose, making progress to a target, and gaining some attitudes those may affect the quality of life. Making sports increases the acceptance of the individual in society and the self-confidence of the individual. According to the results of the analyzes obtained by considering the aspects that some positive effects 
could be put on the performances by using psychological skills such as self-confidence, goal setting, and having a preparation plan in coping with the problems and that how the ones with aforespecified features could have the proactive personality traits, were significantly different according to their grade levels. The proactive personality scores of non-successful athletes have, per aforementioned aspects, lower averages than the athletes with national or international success. It was found in another research that there were some important differences, in terms of self-confidence, among the successful and unsuccessful wrestlers (Highlen and Bennett, 1979; Gould et al., 1981) gymnasts (Mahoney and Avener, 1977) and racketball athletes (Meyers et al., 1979). Individuals can develop some skills by doing sports and use these skills when needed in tough environments. The capabilities such as making decisions under pressure and developing tactics according to different situations may be prerequisites for being successful. It is evident that the self-confidence puts positive contributions to the performance.

It was determined, in our study, that the opinions of the subjects about the proactive personality characteristics did not show any significant difference according to their monthly incomes. Sahin (2006) claimed in his research, in which he investigated the socio-economic level of the individual and proactive personality structure, that there was no correlation between the socio-economic level of the individual and the proactive personality structure. However, Karasu (2013) compared in his survey the autonomy, attachment styles, and proactive personality structures of the students based on their socio-economic status and reached a result that though there was relative difference in terms of autonomy and proactive personality structures for the socio-economic status of the students between the averages of the lower and upper-class groups, there was no statistically significant difference thereof. The results above support our research findings.

As a result, the training administrators can support, starting from the first developmental periods and spreading to the individuals at all levels of education, the sports for which we both observed and understood that it puts some positive effects in the presence of individuals with proactive personality traits. It is considered and suggested that accomplishing more studies in education, psychology, sociology, and sports fields in this direction will put the positive contribution to the understanding, development, and diffusion of the proactive personality traits.

It is thought that the new generations will benefit from the development of their personality traits and their positive characteristics in their lives. The study accomplished can be regarded as the first domestic study on the identification and analysis of the proactive personality traits. It is considered that attaining proactive personality traits at different age groups and at different educational stages are used for acquiring comprehensive outcomes, and the researchers are recommended to carry out more studies in this field.

\section{References}

Akın, A., R. Abacı, M. Kaya and N. Arıcı, 2011. The validity and reliability of the Turkish version of the abbreviated Proactive Personality Questionnaire (PPP). In ICES1 1 International Conference on Educational Sciences, June. pp: 22-25.

Baltaş, A., 2005. The human profile behind entrepreneurship. Retrieved from http://www.baltas-baltas.com.

Baltaş, A., 2008. The human profile behind entrepreneurship. Retrieved from http//:www.baltas-baltas.com.

Bateman, T.S. and M. Crant, 1993. The proactive component of organizational behavior: A measure and correlates. Journal of Organizational Behavior, 14(2): 103-1 18. View at Google Scholar $\mid$ View at Publisher

Bayar, P., 2003. Comparison of personality characteristics of sports and non-sports women. Journal of Sport Sciences Hacettepe, 18(2): 133140.

Cetinöz, F., 2005. Factor analysis of individual and team sports performers a study on cattel's 16 person factor inventory and top level athletes. Master Thesis. Manisa: Celal Bayar University.

Çini, P.E., 2014. Proactive personality attributes of managers and employees and relative dependent self levels. Unpublished Master's Thesis, Maltepe University Institute of Social Sciences.

Crant, J.M., 2000. Proactive behavior in organizations. Journal of Management, 26(3): 435-462. View at Google Scholar |View at Publisher

Gould, D., M. Weiss and R. Weinberg, 1981. Psychological characteristics of successful and nonsuccessful big ten wrestlers. Journal of Sport Psychology, 3(1): 69-81. View at Google Scholar |View at Publisher

Highlen, P.S. and B.B. Bennett, 1979. Psychological characteristics of successful and nonsuccessful elite wrestlers: An exploratory study. Journal of Sport Psychology, 1(2): 123-137. View at Google Scholar $\mid$ View at Publisher

Hoffstetter, C.R., M.F. Hovell and J.F. Sallis, 1990. Social learning correlates of exercise self-efficacy: Early experiences with physical activity. Social Science and Medicine, 31(10): 1169-1176. View at Google Scholar | View at Publisher

Karasu, H., 2013. Investigation of attachment styles and proactive personality structures as a predictor of autonomy in adolescents. Master Thesis. Tokat: Gazi Osmanpaşa University.

Mahoney, M.J. and M. Avener, 1977. Psychology of the elite athlete: An exploratory study. Cognitive Therapy and Research, 1(2): 135-141.

View at Google Scholar I View at Publisher
Meyers, A.W., C.J. Cooke, J. Cullen and C. Liles, 1979. Psychological aspects of athletic competitors: A replication across sports. Cognitive Therapy and Research, 3(4): 36 1-366. View at Google Scholar | View at Publisher

Sahin, G.R., 2006. An investigation of the relationship between individuals' proactive personality structure and self-esteem levels. Master Thesis. Sakarya: Sakarya University.

Schwarzer, R., 1999. Teachers proactive attitude. Emprrische Padagogik. Retrieved from http//www.userpage.fuberlin.de/health/preprint.html.

Van, V.A.E.M. and P.I.E. De, 2012. Content and development of newcomer person-organization fit: an agenda for future research. In Wanberg, C. (Ed), The Oxford handbook of socialization. New York: Oxford University Press.

Webster's Medical Dictionary, 2002. A service of the U.S. National library of medicine, National Institutes of Health. Retrieved from http://www.nlm.nih.gov/medlineplus/mplusdictionary.html. 